\title{
Horses and nomads in Mongolia
}

\author{
Tetsuro Matsuzawa ${ }^{1,2,3}$
}

Published online: 30 August 2019

(C) Japan Monkey Centre and Springer Japan KK, part of Springer Nature 2019

This is a brief report of my recent trip to Mongolia. I had never been to the country before, partly because there are no monkeys or apes. However, it might be a valuable endeavor for understanding primate evolution in comparison to other mammals. For a few years, my colleagues and I have also been focusing on wild horses (Matsuzawa 2017).

The area of Mongolia is about four times larger than that of Japan. It corresponds to the total area of Germany, France, Spain, and Portugal in Europe. The latitude is also similar: the latitude of the capital Uraanbaatar is approximately that of Paris. However, the population of Mongolia is only about 3 million, about $2.5 \%$ of that of Japan.

The primary purpose of my journey was to see Takhi in the wild. Takhi is the Mongolian name of Przewalski's horse (Equus przewalskii). In 1969, the last evidence of Takhi in the wild was recorded in the Gobi Desert. No new observations of wild Takhi have been recorded in the last 50 years. The species is considered to have become extinct in the wild.

However, many Takhi had been captured and sent to zoos in Europe and North America since the species was discovered and reported to the Western world in the 19th century (Boyd and Houpt 1990). A reintroduction trial started in 1992. It is a program initiated by Jan and Inge Bouman from the Netherlands, with the collaboration of Mongolian government (Wit and Bouman 2006). The horses were brought to Hustai National Park, about $100 \mathrm{~km}$ west-southwest of the capital. The area of the park is about $500 \mathrm{~km}^{2}$.

The short stay for 3 nights/4 days in Hustai National Park in July gave me the opportunity to look around the freeranging groups of Takhi. In each group, there is one adult male horse, called Azarga in the local Mongolian language. Azarga corresponds to Stallion in English, and he is accompanied by his multiple females and dependent offspring. This

Tetsuro Matsuzawa

matsuzawa.tetsuro.8w@kyoto-u.ac.jp

1 Kyoto University Institute for Advanced Study, Kyoto, Japan

2 Primate Research Institute, Kyoto University, Inuyama, Japan

3 Japan Monkey Centre, Inuyama, Japan social group is called the one-male unit group, or polygamous family group. The birth season of horses in Hustai is limited to May and June, when about $80 \%$ of births occur. The newborns-foals in English-are easy to recognize even from afar. The groups spread out on the slopes covered by green grasses (Fig. 1). We were able to see about ten different groups. The landscape of Hustai is a mixture of steppe and mountain forests. The northern slopes of the mountains have small patches of forest because of the snow remaining for a longer period keeping water.

The first of 16 horses were reintroduced in 1992. That event was followed by four more reintroductions every 2 years, the last one being in 2000. The total of 84 Takhi have been imported to Hustai. Wit and Bouman (2006) reported that 237 foals were born and the total number of horses in Hustai had reached 159 by the end of 2004, and that $75 \%$ of the horses were wild-born at that point. According to the most recent record of June 16th, 2019, kept by national park guards, there were 34 groups, totaling 261 horses. The group size including foals varies from a minimum of two to a maximum of 17 , with an average of 7.7. In addition to the Azarga horses of the one-male unit groups, there are 95 adult male horses who move around alone or form bachelor groups. Thus, the total number of Takhi in the Hustai

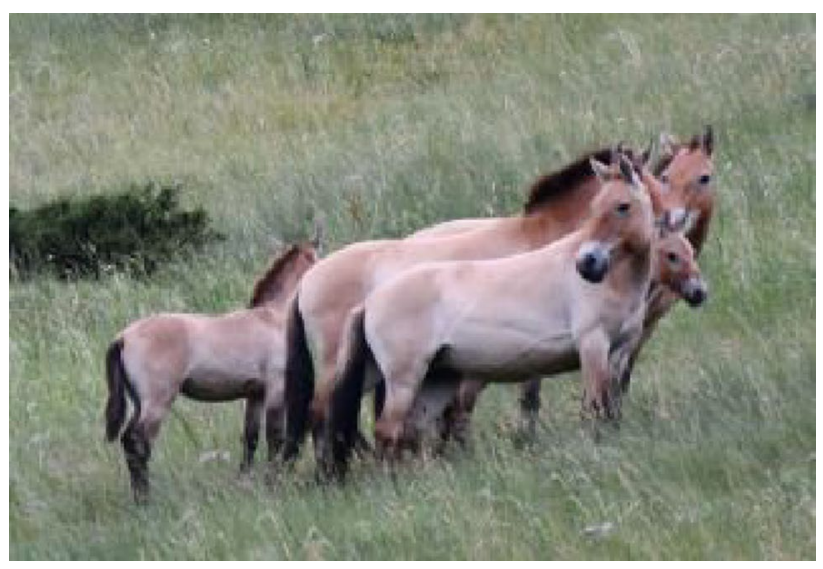

Fig. 1 Takhi, the wild horse in Hustai National Park: All photos of this article were taken by Tetsuro Matsuzawa 
National Park is 356. According to statistics of the National Park, 25\% of the foals were eaten by wild Mongolian wolves (Canis lupus chanco).

Mongolia is situated at the junction of Siberian forests and the deserts and arid steppes of Central Asia. Hustai is one example of a region containing a wide range of natural ecosystems. Grasses and sedges are the most important plants of the Mongolian steppes. In addition to the wild Takhi, we saw wild marals (Mongolian red deer, Cervus elaphus) also grazing the grasses and sedges. The most common animal in Hustai was the tarabagan marmot (Siberian marmots, Marmota sibilica, Fig. 2a). On encountering potential danger, for example, humans, they run to their burrows where they characteristically stand on their hind legs to watch the threats. Marmots must play an important role in nutrient and soil recycling due to their digging and defecating. We also saw other rodents that live underground, such as ground squirrels (Spermophilus undulates, Fig. 2b) and voles (Brandt's vole, Microtus brandtii). Takhi seem to be attracted to these places as a source of minerals and tasty grasses and sedges.

The Hustai was rich in birds, too. There were many kinds of large birds, such as black storks (Ciconia nigra), Demoiselle cranes (Anthropoides virgo), and black-eared kites (Milvuus lineatus). I saw a flock of seven black vultures (Aegypius monachus) and two Himalayan vultures (Gyps himalayensis) starting to eat the dead body of a marmot. So far, 208 species of vertebrates have been recorded in Hustai National Park. These include 15 species of fish, two amphibians, three reptiles, 148 birds, and 43 mammals (Wit and Bouman 2006). The rich fauna of Hustai reminds me of the importance of understanding the whole ecosystem that provides the basis for the survival of wild Takhi.

From Hustai, my colleagues and I moved to Kharhorin. Once called Karakorum, it was the base of Chinggis Khaan (Genghis Khan, born Temüjin, 1162-1227). He was the founder of the Mongol Empire, uniting many of the nomadic tribes of Northeast Asia. He also launched the Mongolian invasions that conquered most of Eurasia.
We moved on to the west and spent 4 nights and 5 days in a place near Khotont in Arkhangai prefecture, in the central part of Mongolia. "Ar" means "north" and "Khangai" means "the mountain forest rich in the water" in Mongolian language. We stayed in a ger, a Mongolian portable house, owned by a nomad named Mr. Enkhbat. He kindly offered a ger for five of us. In that last week of July, the maximum temperature was $23{ }^{\circ} \mathrm{C}$ and the minimum was $13{ }^{\circ} \mathrm{C}$. The temperature remains below zero all day long in the winter season.

Mr Enkhbat's family owned horses, cows, goats, and sheep (Fig. 3). At this altitude (about $1800 \mathrm{~m}$ ), the cows are replaced with yaks and hybrids by some nomad families. We experienced the daily life of nomads. They milk cows twice a day, in the morning and evening. They also milk horses five times a day, once every $2 \mathrm{~h}$ (Fig. 4). Sheep are used for meat and wool, while the goats provide meat and high-quality cashmere.

The meals always contained milk products. Nomads turn milk into cream, yogurt, and cheese. Pounding milk a thousand times makes alcohol: cow milk alcohol and horse milk alcohol, which can be made clear and stronger by distilling them.

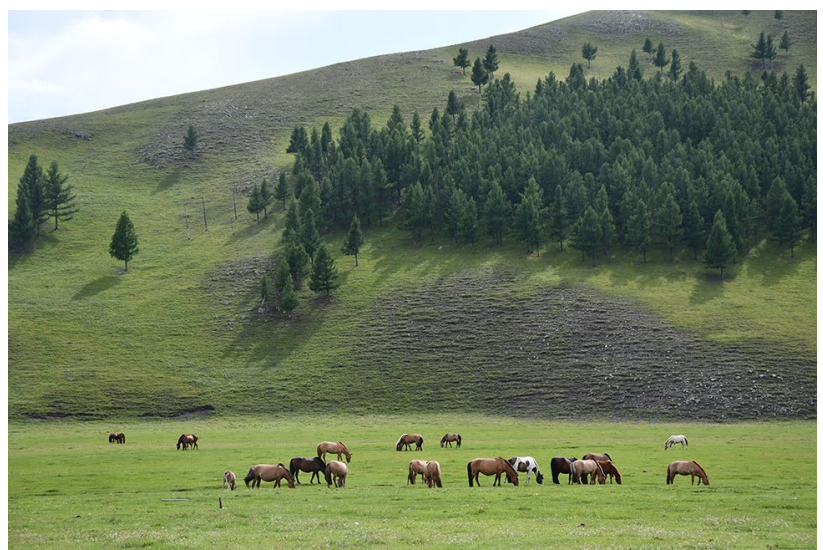

Fig. 3 The view of the grassland and horses from the ger of Mr. Enkhbat
Fig. 2 a Tarbagan marmot. b Ground squirrel
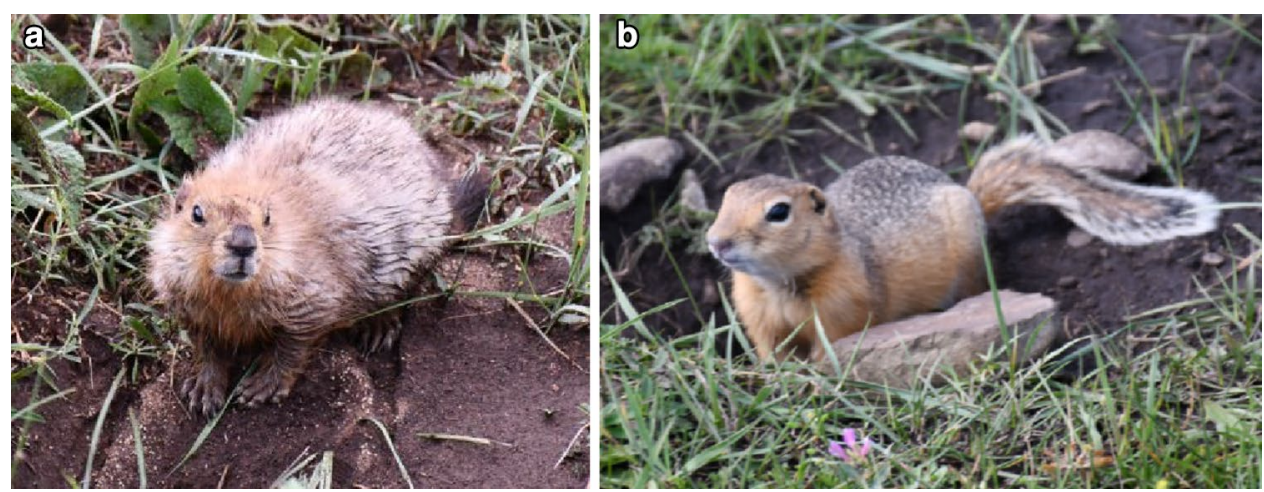


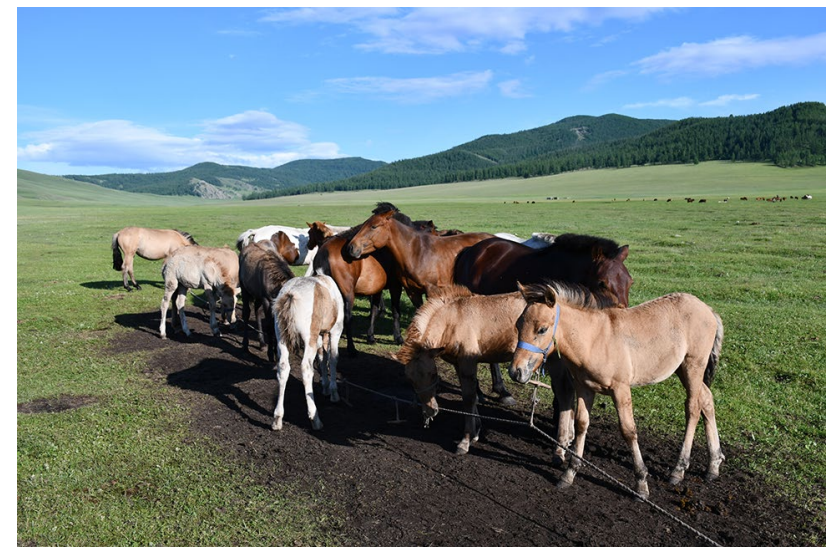

Fig. 4 The foals are tied to a long string to keep their mothers near them. Nomads milk the mother

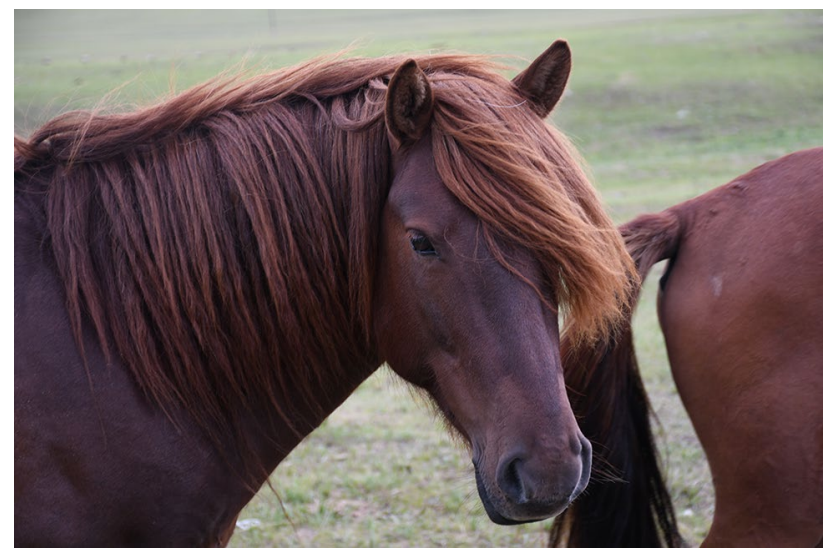

Fig. 5 Azarga the stallion

The Mongolian horses kept by nomads are the descendants of different strains. The group of captive Mongolian horses reminds us of that of wild Takhi. There was always one Azarga (Fig. 5), leading multiple adult females-mares in English-called Gü̈̈, and their offspring. There are different names for offspring at each age: foals born this year are called Onaga, and then as they develop they become Daaga, Shdlen, Khyazaalan, Soyolon, and Ikh-nas.

In my understanding, there was only one fundamental and critical difference between captivity and the wild-that is $A g t$, the castrated male horse. In the wild, in my understanding, Azarga may chase young males out of the natal group when the latter are approaching sexual maturity. However, in captivity, the nomads castrate young males of 3-4 years of age, reducing the likelihood of aggression. Thus, the Agt can continue to stay in the natal group. Nomads use some of the castrated males for horse riding.

Riding horses is one of the fundamental skills of young nomads. A 6-year-old boy named Dashjirev, a nephew of Enkhbat, rode a horse to herd the cows, horses, goats, and

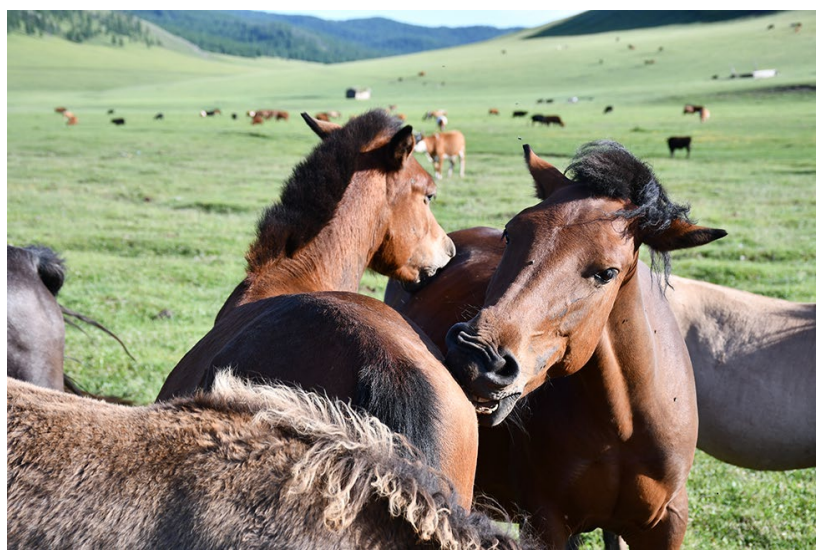

Fig. 6 Mutual grooming (Allogrooming) by teeth

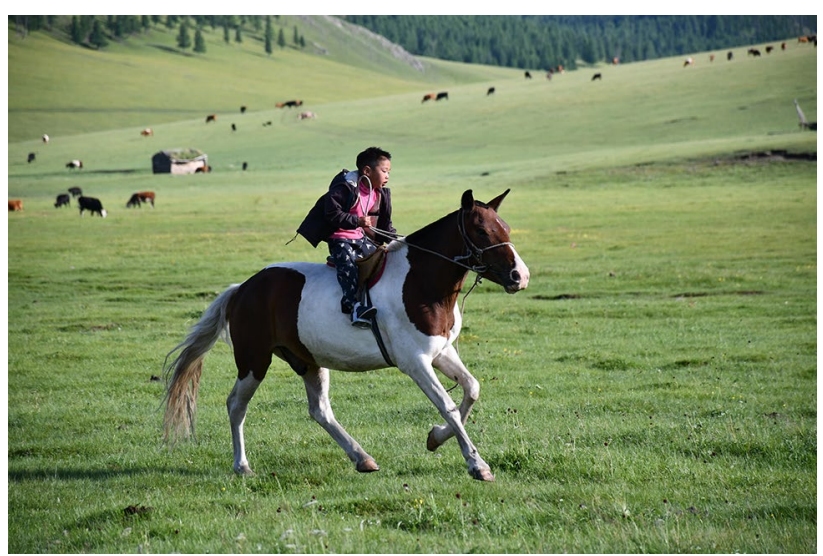

Fig. 7 A 6-year-old boy riding on the Mori to herd horses, cows, sheep, and goats

sheep (Fig. 6). The horses that are ridden have their own name: Mori. I tried to ride Mori, too. It is amazing to see young boys sometime riding the horses without saddles.

Nomads keep Mongolian horses as free as possible. The horses graze freely on the grassland, and it was easy for us to observe some of their social behaviors. They like grooming each other, using their teeth (Fig. 7). Neighboring groups have agonistic relations, just like wild horses.

I tried to use a drone to take overhead photos and movies to clarify their spatial distribution (Figs. 8, 9). The horses were not alarmed by the drone approaching. Drone use will be increasingly valuable for studies of horses and other grazing mammals.

The Family Hominidae consists of four genera; human, chimpanzee, gorilla, and orangutan. Horses (Equus ferus caballus) belong to the Family Equidae, which contains the single genus Equus. The genus Equus includes horses, zebras, and donkeys. My colleagues and I targeted horses for study in 2014 (Matsuzawa 2017; Tomonaga et al. 2015; Ringhofer et al. 2017), leading to field studies in Portugal, 


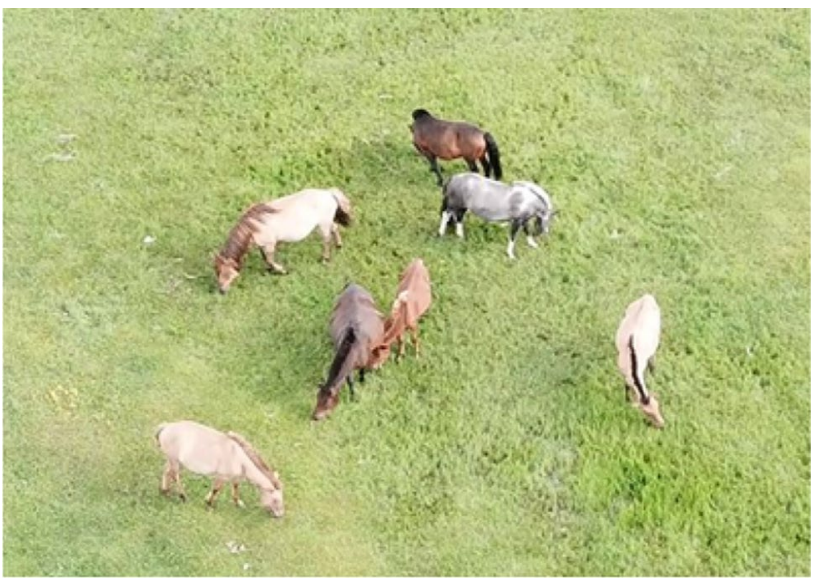

Fig. 8 An aerial view of Mongolian horses by the drone. Azarga with long mane is located in the top left

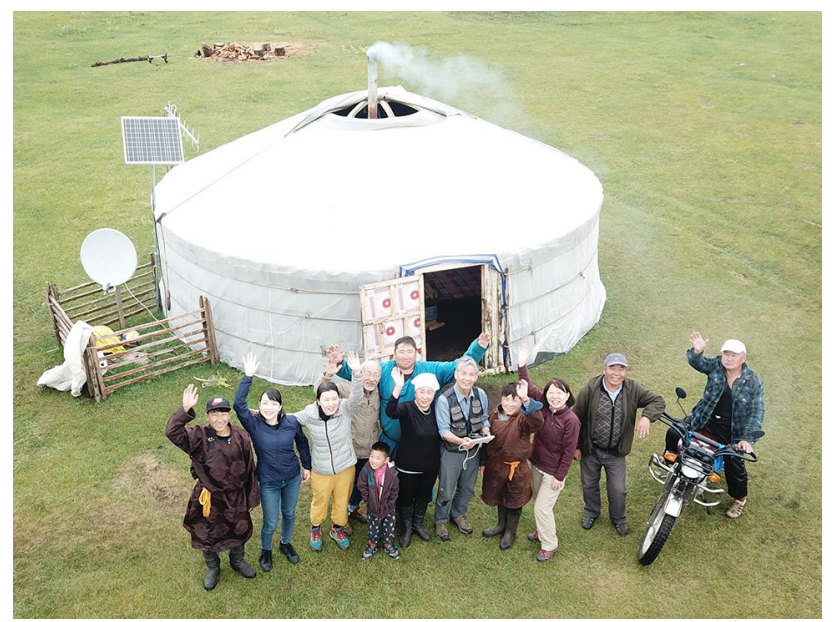

Fig. 9 An aerial view of the team for the present study

Spain, Japan, and now Mongolia. We have been clarifying the social structure of Garanos horses in Serra d'Arga, northern Portugal, by using drones and direct observations of individually identified horses (Inoue et al. 2019; Mendonça et al. 2019).

The one-male unit of horses reminds me of the social structure of wild gorillas. I have visited the two ecotourism sites of the mountain gorillas, in Virunga volcanoes in Rwanda and Bwindi in Uganda. Gorillas and horses look similar in some respects. For example, both have a large body size and live on grasses, sedges, or herbs. The social group resembles a family group that consists of one adult male and several females and offspring. The Azarga of horses is the silverback of gorillas.

However, closer observation reveals a critical difference between Azarga and Silverback. Juichi Yamagiwa, the gorilla expert, used to describe silverback behavior as stable, like a rock. The silverback is found in the center and surrounded by the other members of the group, especially the young offspring. In contrast, Azarga almost always keeps a peripheral position in the group, moving around herding the females, keeping the group away from neighboring groups, and chasing away bachelors from the outside.

Further studies of horses may bring us new insights into the mammalian origins of primate society and social behavior. For me, the critical question is the existence of regionwide communities of multiple groups. Human society is characterized by such multi-level society: a family exists within the community, which in turn has neighboring communities. Such investigation of wild horses and other species may thus shed light on human evolution from the wider perspective of mammalian evolution.

Acknowledgements This journey was fully arranged by Prof. Yuki Konagaya, National Museum of Ethnology, who is the expert on Ethnological studies of nomads in Mongolia. She has spent more than 40 years in various places in Mongolia. Without her guidance it would have been impossible to gain such knowledge on the horses and the nomads in Mongolia in such a short period. Dr. Ayumi Hotta, supervised by Prof. Konagaya, has been doing fieldwork in Arkhangai prefecture. She introduced us to the nomad, Mr. Enkhbat. The two scholars took the role of translating from Mongolian on site and giving lectures on the people and culture of Mongolia. The entire journey was undertaken by another two scholars, Prof. Eiji Hosoda from Chubu University, who majors in Environmental Economy, and Dr. Monamie Ringhofer from Kyoto University, who majors in Ethology of horses. I thank those people for giving me the precious experience in Mongolia. Thanks are due to Mr. Enkhbat and his family, relatives, and friends in Arkhangai. We stayed in the ger provided by him, and visited the gers of others to learn more about the everyday life of nomads. We also appreciate two drivers who took us to the remote places. I also thank my colleagues who are promoting Equinology with me: Masaki Tomonaga, Satoshi Hirata, Shinya Yamamoto, Monamie Ringhofer, Renata Mendonça, Sota Inoue, Tamao Maeda, Sakiho Ochi, Pandora Pinto, Carlos Pereira, Helena Freitas, Coby Bolger, Lucy Rees, and Enrique Alonso García. Financial support for this survey was given by MEXT grant for the specially promoted program 16H06283, JSPS leading graduate program of PWS (U04), JSPS core-to-core program for Comparative Cognitive Science Network, and Kyoto University Onsite Laboratory for Comparative Cognitive Science. Finally, I want to thank Prof. James Anderson for carefully reading the manuscript and editing English text.

\section{References}

Boyd L, Houpt KA (1990) Przewalski's horse: the history and biology of an endangered species. State University of New York Press, Albany

Inoue S, Yamamoto S, Ringhofer M, Mendonça R, Pereira C, Hirata S (2019) Spatial positioning of individuals in a group of feral horses: a case study using drone technology. Mamm Res 64:249-259 
Matsuzawa T (2017) Horse cognition and behavior from the perspective of primatology. Primates 58:473-477. https://doi.org/10.1007/ s10329-017-0632-9

Mendonça R, Ringhofer M, Pinto P, Inoue S, Hirata S (2019) Feral horses' (Equus ferus caballus) behavior toward dying and dead conspecifics. Primates. https://doi.org/10.1007/s10329-019-00728 $-\mathrm{X}$

Ringhofer M, Inoue S, Mendonça R, Pereira C, Matsuzawa T, Hirata S, Yamamoto $S$ (2017) Comparison of the social systems of primates and feral horses: data from a newly established horse research site on Serra D'Arga, northern Portugal. Primates 58:479-484. https ://doi.org/10.1007/s10329-017-0614-y
Tomonaga M, Kumazaki K, Camus F, Nicod S, Pereira C, Matsuzawa $\mathrm{T}$ (2015) A horse's eye view: size and shape discrimination compared with other mammals. Biol Lett 11:20150701. https://doi. org/10.1098/rsbl.2015.0701

Wit P, Bouman I (2006) The tale of the Przewalski's horse. KNNV Publishing, Utrecht

Publisher's Note Springer Nature remains neutral with regard to jurisdictional claims in published maps and institutional affiliations. 